\title{
"ECCE CORPUS": DEL CUERPO DEL LIBRO HACIA LA OBRA DE ARTE TOTAL
}

\author{
Mercédesz Kutasy \\ Universidad Eötvös Loránd \\ mkutasy@gmail.com
}

Resumen: En 1975 Raúl Zurita se quema la cara y la fotografía hecha sobre su llaga aparecerá en 1979 en la portada de Purgatorio. Virgilio Piñera publica Cuentos fríos con una conocida carencia en la portada, la de la fotografía de su cuerpo desnudo. En el presente estudio observo diferentes fases de la hibridez del género literario: la transformación de la imagen — la autorrepresentación del artista, la fotografía personal- en documentación, en performance o en ficción. A la vez analizaré cómo se van ampliando los campos semánticos de ambas obras para abarcar finalmente la totalidad de la creación a través de la presencia y la totalidad del vacío a través de la ausencia.

Palabras clave: autorrepresentación, hibridez de géneros, cambio de escala, Virgilio Piñera, Raúl Zurita

\begin{abstract}
In 1975, Raúl Zurita burns his face, and the image of his scar will appear in 1979 on the cover of his Purgatorio (Purgatory). Virgilio Piñera publishes Cuentos fríos (Cold tales) with a well-known lack on its cover: the lack of the photo of his nude body. In this paper I will analyze different phases of a literary genre's hybridity: the transformation of the image - the artist's self-representation, the personal photography - in documentation, in performance or in fiction. At the same time I will analyze how the semantic fields of both artworks are increasing in order to encompass in the end the totality of the creation by the presence and totality of the emptiness, and by its absence.
\end{abstract}

Keywords: self-representation, generic hybridity, scale change, Virgilio Piñera, Raúl Zurita.

\section{DOI: $\underline{\text { https://doi.org/10.24029/lejana.2017.10.169 }}$}

Recibido: el 30 de julio de 2017

Aceptado: el 1 de octubre de 2017

Publicado: el 4 de noviembre de 2017 
Para que mi facha comience a tocar tu facha y tu facha a esa otra facha y asi hasta que todo Chile no sea sino una sola facha con los brazos abiertos: una larga facha coronada de espinas.

(Zurita: Purgatorio, 40)

Dibujar una cara es un acto que necesariamente nos recuerda a aquel que formó la primera cara humana a su propia imagen y semejanza y le sopló el alma; por eso sorprende cuando el uso artístico de la cara no es una doble mímesis, imagen de la imagen, sino que va en dirección inversa, procurando mostrar algo más grande que ella misma, la cara humana tratando de evocar la de aquel a cuya semejanza fue tallada.

Raúl Zurita se quema la cara en mayo de 1975, acto considerado como protesta personal que se hace pública fotografiando la llaga, que aparecerá desde cerca, casi irreconociblemente, en 1979, en la portada de la primera edición de Purgatorio. El artista recuerda ese evento como reacción personalísima en una situación límite:

Quemarme la cara fue un acto solitario y desesperado, no fue una performance, no hubo cámaras fotográficas, nada, y no tuvo más espectadores que yo mismo, mejor dicho, de algo que a duras penas en ese instante podía llamar yo mismo. Fue en mayo del 1975, un año y medio después del golpe militar, luego que unos soldados me habían sometido a una de esas típicas vejaciones en la que son expertos. Me acordé de la famosa frase del evangelio: si te abofetean la mejilla derecha pon la mejilla izquierda. Entonces quemé mi mejilla izquierda, estaba completamente solo, me encerré en un baño y me la quemé con un fierro al rojo. ${ }^{1}$ (Solanes, 2008: 105-106)

En ediciones posteriores, la portada del tomo reproduce una fotografía de carné de Zurita, ${ }^{2}$ la misma que aparece en el interior del libro con la emblemática inscripción "EGO SUM - QUI SUM", la vocación autorretratística de la portada recuerda sin embargo a otro performer de las letras hispanoamericanas, Virgilio Piñera, quien en 1956 pretende (aunque no lo logra) que en la portada de otro primer volumen, esta vez de cuentos, apareciese la fotografía —o, en su defecto, la radiografía - de su cuerpo desnudo. ${ }^{3}$

Piñera trabaja con caras y cuerpos no solo en la mencionada portada sino en sus textos literarios para perfilar el miedo: dobles, sustitutos, figuras y rostros demasiado generalizados; el ejemplo más característico tal vez sea el de su cuento titulado "La cara", donde el protagonista, de profesión escritor, se deja seducir por una cara "temible" (Piñera, 2006: 58) a través del teléfono, y finalmente opta por la automutilación, la ceguera, para poder lograr una,

\footnotetext{
${ }^{1}$ Aunque el artista afirme que quemarse la cara no era un performance, sí lo era una larga serie de intervenciones públicas sobre su propio cuerpo, en los años siguientes. Es el caso de No, no puedo más (1979), cuando en la Galería Cal de Santiago de Chile el artista eyacula frente al público, esparciendo su semen en su cara cortada y quemada (Jones, 2006: 128), aunque en otras versiones Zurita asegura que la masturbación no tuvo lugar en público sino era presentada a base de fotografías sobre la misma; o cuando el artista se tira ácido en los ojos para cegarse y no poder ver su acción en la que cinco aviones dibujan en el aire de Nueva York los versos de La vida nueva (las fotografías se publican posteriormente en Anteparaíso y los ojos del artista se salvan).

${ }^{2}$ Por ejemplo, la publicada por Visor Libros, 2010.

${ }^{3}$ La intención, sin embargo, se divulga y forma parte de las leyendas sobre el cubano: en este aspecto participa de la creación artística, al igual que las ideas y las ideas no realizadas de Ben Vautier, entre los años 1957 y 1970 .
} 
al menos dudosa, unión feliz; ${ }^{4}$ lo mismo que acomete el yo poético de Zurita que destroza su "cara tremenda" (Zurita, 2010: 17) frente al espejo. La cara expuesta en el cuento de Piñera parece muy concreta, sin embargo, para el final, el lector se da cuenta de que todos los adjetivos que la caracterizan ("temible", "sobrecogedora") pueden tener tanto un matiz positivo como negativo, es decir, estamos frente a una generalización extrema que se disfraza de una persona en particular.

El artista plástico húngaro Tibor Csiky expone en Buenos Aires, en 1973, un trabajo formalmente muy similar a las primeras páginas del Purgatorio de Zurita: pega en una hoja en blanco la fotografía de su carné de transporte público con la inscripción "I was born in the XXth century in Europe. That's enough". Con este acto participa de la paradoja practicada por Piñera: la foto siembra la certeza de una reproducción concreta, aparentemente documenta e identifica al artista; a su vez, la frase que en un principio tiende en la misma dirección, anula la fotografía, las informaciones demasiado genéricas no son aptas para identificar a nadie. La foto concreta con las frases genéricas carga la obra de un significado mutable (aunque en la fotografía aparece un hombre llamado Tibor Csiky, bien podría aparecer cualquier otra persona), a la vez que la amplía hasta el sinsentido o hasta formular cuestiones absolutamente generales sobre la existencia o sobre el arte (qué significa ser europeo, cuál es el papel del artista en la sociedad, cuál es la relación entre el individuo y la sociedad, etc.).

Arnaldo Donoso Aceituno y Ricardo Espinaza Solar aluden en su artículo (2015) al trabajo de la artista argentina Mónica Millán (1960), titulado Picnic a orillas del río Paraná (2007). Millán esboza en su instalación no su propio autorretrato sino el de un pueblo: "con tejedores tradicionales del Paraguay, cultores del bordado Ao Pa'i [...] integra piezas textiles y sonidos de agua para recrear el paisaje original" (Donoso Aceituno y Espinaza Solar, 2015: 73), siendo este el mismo método empleado por Zurita: el chileno trata el paisaje en varias obras como si fuera una extensión del cuerpo humano, como si el paisaje y el rostro del artista funcionaran de forma análoga. Cuando Zurita se quema la cara y cuando deja inscripciones en las rocas del desierto de Atacama ("Ni pena ni miedo"), expone el mismo dolor, la misma subversión y sensibilidad. Dañarse se convierte así en una especie de parábola, el artista se transforma en un gran signo de exclamación para indicar tantos otros sufrimientos que pasan desapercibidos.

Millán pretende recrear en su obra citada la presencia de algo que no está, del mismo modo en que lo hace la artista húngara Dóra Maurer en su "project for PRESENT-PIECE for CAYC/Buenos Aires": crea su presencia en Buenos Aires — donde, por razones políticas, no puede estar - a través de las fotografías en gran escala de fragmentos de su cuerpo, muestras de su propio pelo y sangre, y la constante documentación de todos los actos que realice a lo largo de la duración de la muestra, de la que ella, autora de la instalación, faltará.

Los ejemplos anteriormente citados muestran dos de los métodos más frecuentes para reflexionar sobre el propio cuerpo: por una parte, la generalización que va de lo propio y personalísimo para diluirse acto seguido en lo insignificante o en lo general, y por otra, en el uso de diferentes "comodines" (documentación fotográfica, sonidos, materiales, fragmentos) para recrear la presencia de lo distante.

\footnotetext{
${ }^{4}$ Sobre una posible interpretación de este texto a base del mito de Narciso véase en Kutasy (2016): Interrogando imágenes. Murcia, Editum, 163-182; a la vez es llamativo recordar la semejanza entre el gesto narrado por Piñera y el intento de cegarse del poeta Zurita.
} 
Sin embargo, los dos autorretratos de las dos portadas (la foto de la cara de Zurita y el deseo no cumplido de Piñera) comparten una característica más, que con toda seguridad contribuye a comprender su funcionamiento. Creemos entender lo que ve y por lo que se pierde Narciso, el bello joven, mientras contempla sus perfectas facciones en el agua -que bien puede ser la superficie de la hoja del libro, la del lienzo-, sin embargo, tanto en Piñera como en Zurita, aparece una peca en ese contemplar. Zurita, en la portada de Purgatorio, no expone la belleza de su cara sino solo un fragmento, la llaga que ha quedado tras quemarla. De hecho el primer texto del tomo dice así:

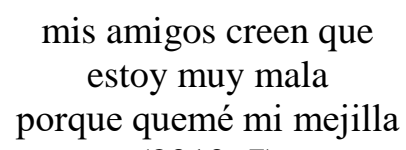
(2010: 7)

Zurita no expone un autorretrato tipo Narciso, no posa, no quiere verse favorable, más bien todo lo contrario: muestra la falta, muestra la debilidad. Los primeros poemas de Purgatorio son testimonio de un equilibrio muy débil entre la locura y la razón; las dos páginas ya citadas (EGO SUM - QUI SUM) presentan la paradoja de la fotografía del carné de Zurita a la izquierda (hombre joven, barbudo, grandes ojos oscuros) y el manuscrito de una supuesta Raquel a la derecha ("Me llamo Raquel / estoy en el oficio / desde hace varios / años. Me encuentro / en la mitad de / mi vida. Perdí / el camino. -"). El narrador extiende la autoridad de su yo poético hasta tal punto que termina abarcando lo masculino (foto) y lo femenino (Raquel), el fragmento de la herida (foto de la portada) y el retrato oficial (interior del libro), la locura (informe de Ana María Alessandri, psicóloga de Zurita), la enfermedad (su EEG) y la normalidad forzada (poemas escritos a base de ideas matemáticas), la razón y el sueño, la realidad (la vida de Zurita) y la ficción (sus alter-egos, la distancia creada por la literatura y por el soporte en forma de libro) y también el ser humano (ya sea masculino o femenino) y la naturaleza ("Desiertos"). Incluso en esta hibridez textual que es Purgatorio, algunas páginas en sí presentan una complejidad palimpséstica; basta pensar en el informe psiquiátrico en el que Zurita tacha y cambia su nombre por una variedad de nombres femeninos (tachadura Violeta - Dulce Beatriz - Rosamunda - Manuela) y en la parte inferior de la página sobreimprime la frase "TE AMO TE AMO INFINITAMENTE", cuya procedencia no se precisa, sin embargo, en relación a esta frase, Zurita comenta que Purgatorio se generó tras la dictadura, en una situación en la que ni la literatura ni la poesía era capaz de expresar el dolor. "Siento que tuve que aprender a hablar de nuevo desde el quiebre total, desde casi la locura, para poder decirle todavía algo a alguien" (Solanes, 2008: 103); muestra de ese nuevo aprendizaje son las frases citadas. Zurita busca en las páginas heterogéneas de Purgatorio, a través de intentos diversos, su voz; busca definir la identidad de esa cara que aparece quemada en la portada e íntegra en el interior del volumen. Zurita, en todo caso, llega hasta el límite en esta búsqueda, como lo expresa Richard, "su lenguaje poético/visual constituye una «salida-de-marco»" (1994: 42), es una "metáfora de la transgresión a los márgenes institucionales y disciplinares" (Espinoza Solar y Donoso Aceituno, 2015: 72). Zurita mismo define el arte a través de fisuras, de hecho considera el dolor como ingrediente imprescindible de la creación artística: "La historia del arte es la historia oficial del dolor, de lo contable de él. Sin dolor no hay arte. Es la fisura a través de la cual emerge lo expresable, si no hay herida 
no hay expresión. Eso es así, pero el deber de lo humano es la felicidad, no el arte" (Solanes, 2008: 102).

En este contexto, la herida de la cara aparece en la portada del primer libro como una puerta a través de la cual se abre el acceso hacia el mundo del arte: en este doloroso universo de la sensibilidad presenciamos una lucha por cada palabra; a la vez, paradójicamente, la autenticidad se vislumbra tras un sinfín de máscaras, la verdadera cara de Zurita se va montando por medio de la de Raquel, Violeta, Dulce Beatriz, Rosamunda, Manuela, de tantos desiertos y pampas, de vacas pastando y del cielo estrellado. Al mismo tiempo, a través de la quemadura también se abre un refugio: "Escribir es suspender la vida, es algo real, si tú estás preocupado porque te cortaron el gas por falta de pago, no escribes, cuando comienzas a escribir es cuando te olvidas del gas. Pero al suspenderse la vida también se suspende la muerte" (Solanes, 2008: 104).

La creación de ese nuevo "yo" a través del arte es a la vez una forma de sobrevivir: es lo que está practicando día a día Tota y Tabo en Dos viejos pánicos de Piñera, cuando buscan suspender la vida (y el miedo) en el juego de matar (quemar) las figuras de papel recortadas o en el juego de matarse el uno al otro. El juego concreto en este caso funciona como la literatura, ya que, según la definición de Zurita, logra suspender la vida, a la vez que las muertes (suicidios fingidos y asesinatos ficticios) practicadas con regularidad terminan aboliendo la Muerte: la aniquilación y consumación del ser humano en su constante miedo. En Zurita, paralelamente, la literatura es juego según el término gadameriano, es fiesta, es un universo aparte, lógico, consecuente y auténtico.

En las dos portadas de las primeras ediciones vemos cuerpos atormentados, cuerpos que llevan estigmas: Zurita enseña su herida a modo de un Cristo contemporáneo, haciendo pública su vulnerabilidad; y Piñera quiere desvelar un cuerpo considerado por él como feo, el cuerpo tachado de homosexual y por tanto prohibido y limitado por el régimen castrista. Ambas llagas, que han logrado abrir el acceso a la expresión artística, cierran puertas en la vida de ambos artistas. Zurita es encarcelado y torturado, y cuando, una vez libre, trata de sobrevivir robando y vendiendo libros caros, le fichan en todas las librerías, para no poder comprar su propio tomo (Purgatorio) recientemente publicado (Araya Basualto, en línea). Lo mismo ocurre con Piñera, cuyos libros desaparecen de los ficheros de las bibliotecas tras la Ley de Trabajo (1971) que le tilda de peligroso por homosexual y le impide presentar sus obras en los teatros de Cuba. Al mismo tiempo, como Cristo enseña sus heridas a Tomás, muestra Zurita su cara quemada a todos nosotros, lanzada en la misma portada de un primer tomo, en un gesto que imita abiertamente a ese Salvador que parece, murió en vano por las maldades del mundo. Y Piñera también, pretende posar para decir "Ecce Homo", acá está el hombre — recordemos a Tibor Csiky y su foto con la frase que dice: acá estoy yo, el europeo-, "Ecce Corpus", en un gesto irónico (y aun más irónico, si puede ser, por no realizado). ${ }^{5}$

En los ejemplos observados, el cuerpo del artista es generador e inspirador del acto

\footnotetext{
${ }^{5}$ Zurita utiliza conscientemente ese papel mesiánico de la poesía. Como declara en una entrevista, "[1]a poesía es la más grande imagen de la piedad y al mismo tiempo los horrores del mundo la sobrepasan. Antígona es la compasión por los miles de cuerpos sudamericanos que no han tenido más sepultura que la de los paisajes. Romeo y Julieta es la compasión por esos dos jóvenes, una croata y un serbio, muertos sobre un puente mientras trataban de huir de Sarajevo. Esas obras no están en pasado, nos aguardan aún en el futuro" (Solanes, 2008: 117).
} 
poético, a la vez que se transforma en soporte de la poesía. Aunque Zurita afirme que quemarse la cara fue una reacción no artística (por indocumentada) a una situación personal, con el hecho de colocar la fotografía de la herida (documentación a posteriori) en un producto artístico (el libro), convierte lo personal en puramente estético. Su último tomo rima con su primer afán retratístico: el libro Zurita ${ }^{6}$ concluye con un grandioso proyecto de 22 frases que solo pueden ser vistas desde el mar. El cuerpo del artista participa en una ampliación que va desde la construcción de una identidad personal (yo soy mi mejilla quemada, yo soy las heridas de mi cuerpo) para llegar a abarcar la naturaleza, mares y acantilados incluidos, tal como se anticipa ya al final de Purgatorio ("mi mejilla es el cielo estrellado y los lupanares de Chile", 69); a través de esta ampliación que parte de las diminutas líneas del autorretrato, el poeta terminará esbozando una cara que es todas las caras, infinitamente mayor que él. A la vez Piñera, que aparentemente cede a la voluntad de sus editores y no publica su cuerpo en la portada, pinta su cara en negativo recurriendo a la sustitución: siembra la anécdota de querer publicar el tomo con su propia foto, mientras en el interior de Cuentos fríos varios textos tratan de cuerpos desmontables, dobles, análisis de movimientos (de otros cuerpos); así, tras la lectura del libro se perfila un hueco con la forma de Piñera, una carencia imprecisa que crece hasta transformarse en vacío infinito; desde lo accidental de un cuerpo que no está, hasta lo indispensable del Cuerpo ausente.

\section{Bibliografía}

ARAYA BASUALTO, Rebeca: "Raúl Zurita: «Si no hago nada nuevo, me siento peor que muchos que desprecio»". La Segunda, 5 de abril de 2014: http://www.lasegunda.com/movil/detallenoticia.aspx?idnoticia=926337 (última consulta: 01/09/2017).

ESPINAZA SOLAR, Ricardo y Arnaldo Donoso Aceituno: "Escribir el cielo, escribir el desierto, escribir el acantilado. La escritura material de Raúl Zurita". Ecozono VI/2 (2015): 67-80.

GADAMER, Hans-Georg (1991): La actualidad de lo bello. El arte como juego, símbolo y fiesta. Barcelona, Paidós.

JONES, Amelia (2006): El cuerpo del artista. Londres, Phaidon.

PIÑERA, Virgilio (2006): Cuentos fríos. México, Lectorum.

RICHARD, Nelly (1994): La insubordinación de los signos (cambio político, transformaciones culturales y poéticas de la crisis). Santiago, Cuarto Propio.

SOLANES Ana: "Raúl Zurita: «Escribir es suspender la vida»". Cuadernos Hispanoamericanos 702 (diciembre 2008): 99-117.

ZURITA, Raúl (2010): Purgatorio. Madrid, Visor.

\footnotetext{
6 “En los últimos años estoy en un asunto quizás más desolado, un proyecto cuyo título es Zurita y que se acerca peligrosamente a las 800 páginas. Debería concluir con la escritura de un poema sobre los acantilados que dan al mar. Son 22 frases que sólo podrán ser vistas desde el mar. Se llama Zurita no porque crea que mi vida tenga algo especial, sino porque creo que si pudiésemos llegar al fondo de nuestra experiencia, esa experiencia no sería otra que la de la humanidad entera" (Solanes, 2008: 113).
} 
(C) Mercédesz Kutasy

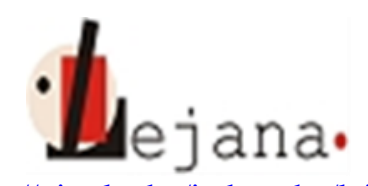

http://ojs.elte.hu/index.php/lejana

Universidad Eötvös Loránd, Departamento de Español, 1088 Budapest, Múzeum krt. 4/C 